\title{
Primary Nonfunction and Early Allograft Dysfunction after Liver Transplantation
}

\author{
Łukasz Masior $^{\mathrm{a}}$ Michał Grąt ${ }^{\mathrm{b}}$ \\ aDepartment of General, Vascular and Oncological Surgery, Medical University of Warsaw, Warsaw, Poland; \\ ${ }^{b}$ Department of General, Transplant and Liver Surgery, Medical University of Warsaw, Warsaw, Poland
}

\section{Keywords}

Primary nonfunction - Liver transplantation - Risk factors .

Graft dysfunction · Retransplantation

\begin{abstract}
Background: Despite continuous progress in the field of liver transplantation, considerable proportion of patients still suffer from the postoperative graft dysfunction. Clinically, it presents as early allograft dysfunction (EAD), and its more severe form defined as primary nonfunction (PNF). Posttransplant liver dysfunction translates into significantly worse treatment outcomes. Summary: Both entities are multifactorial, with donor (graft), recipient, and procedurerelated factors playing the key roles. Ischemia-reperfusion injury is a major driver of their development. So far, various noninvasive (pharmacological) and invasive strategies have been tested to mitigate its negative effects. This article presents the current approach to diagnosis, prediction, and management of EAD and PNF. Key Messages: Different pharmacological interventions may be considered to improve graft function after liver transplantation. Machine perfusion seems to be the most effective method at the moment.
\end{abstract}

\section{Introduction}

Liver transplantation is the only effective treatment of end-stage liver failure and provides good long-term results [1]. Despite substantial progress in scientific research and the continuous improvement of the results of liver transplantation, dysfunction of implanted organ is still a significant clinical problem. Some patients may encounter liver failure immediately after reperfusion which is defined as primary nonfunction (PNF) or the function is impaired in the initial period after transplantation what is manifested as an early allograft dysfunction (EAD). Graft insufficiency leads to greater number of postoperative complications, increased mortality, and risk of organ loss $[2,3]$. Therefore, actions aimed at the prompt diagnosis and implementation of appropriate treatment are crucial for improving the results. This review presents contemporary views on the causes, diagnosis, and management of patients with PNF and EAD.

\section{Definition and Epidemiology}

EAD and PNF can be diagnosed in the case of abnormal postoperative liver function after excluding other causes such as vascular complications, rejection, or infec-

Correspondence to:

Łukasz Masior, lmasior@gmail.com 
tion $[4,5]$. In EAD, marginal graft function manifests in the early days after transplantation. However, thanks to the regenerative capacity of the liver, early re-transplantation can be avoided in a significant proportion of patients $[3,6]$. With regard to the grafts with non-life-sustaining function (PNF), early re-transplantation is the only solution to avoid a fatal outcome $[6,7]$.

\section{PNF Definition}

PNF is the most severe form of EAD. According to the definition of Ploeg et al. [6], PNF is diagnosed in organs that have failed to sustain their function, leading to death or re-transplantation within 7 days of the primary procedure. Some authors assume the period of 10, 14, or even 30 days from the primary operation, in which liver failure leading to death or the need for re-transplantation is defined as PNF [8-11]. In turn, the Organ Procurement and Transplantation Network (OPTN) defines PNF based on the presence of AST activity $\geq 3,000 \mathrm{U} / \mathrm{L}$ and at least one additional criterion: international normalized ratio (INR) $\geq 2.5$, arterial blood $\mathrm{pH} \leq 7.3$, venous blood $\mathrm{pH} \leq 7.25$, and lactate concentration $\geq 4 \mathrm{mmol} / \mathrm{L}$ within 7 days after transplantation [12]. Regardless of the definition used, there is consensus that PNF is a fatal complication unless the patient receives a new organ.

\section{EAD Definition}

Similar to PNF, no uniform, generally accepted definition of EAD has been established so far. Moreover, in the literature, there are various additional terms for early graft dysfunction, e.g., "Initial poor function" [13]. Deschenes et al. [14] created the definition based on bilirubin concentration $>10 \mathrm{mg} / \mathrm{dL}$, prothrombin time (PT) $\geq 17 \mathrm{~s}$, and symptoms of hepatic encephalopathy. EAD defines the presence of at least one of the criteria between 2 and 7 day after transplantation. Cieślak et al. [15] define graft dysfunction as the activity of aspartate aminotransferase (AST) or alanine aminotransferase (ALT) $>2,500$ $\mathrm{U} / \mathrm{L}$ or $\mathrm{PT}<50 \%$ in the first 7 days after transplantation. Ploeg et al. [6] defined EAD based on the AST activity $>2,000 \mathrm{U} / \mathrm{L}, \mathrm{PT}>16 \mathrm{~s}$, and ammonia concentration $>50$ $\mu \mathrm{mol} / \mathrm{L}$ between 2 and 7 days after transplantation. In turn, according to Nanashima et al. [16], EAD is defined as the activity of AST and/or ALT >1,500 U/L in two consecutive measurements in the first 3 days after transplantation. Another definition from the Vienna group is based on the AST level $>2,500 \mathrm{U} / \mathrm{L}$, the necessity to transfuse fresh frozen plasma $>2$ days, and bile production $<20 \mathrm{~mL} /$ day. The parameters were assessed during the first 3 days after transplantation [17]. Among a number of defini-

Graft Dysfunction after Liver

Transplantation tions, currently, the most popular one is that proposed by Olthoff et al. [3] from Pittsburgh. According to this definition, EAD can be diagnosed by meeting at least one of the following criteria: bilirubin concentration $\geq 10 \mathrm{mg} / \mathrm{dL}$ on day 7, INR value $\geq 1.6$ on day 7 , and AST or ALT activity $>2,000 \mathrm{U} / \mathrm{L}$ in the first 7 days after transplantation [3].

The prevalence of PNF varies, depending on the definition, from about $2 \%$ to over $9 \%[7-11,18,19]$. As for the frequency of $\mathrm{EAD}$, it ranges from 15 to $30 \%$ after transplantations from donors after brain death (DBD), reaching even $68.4 \%$ after transplantations from donation after cardiac death (DCD) donors [3, 20-23]. Selected EAD definitions are presented in Table 1.

\section{Graft Failure Prediction}

All the definitions listed above are static and binary in nature. In practice, this means that only patients who meet specific criteria are diagnosed with EAD. This approach excludes the group of patients who do not meet the definition, who nevertheless have impaired function of the graft with all its consequences. On the other hand, some patients, e.g., with high bilirubin concentration before transplantation, have a favorable postoperative course and a good prognosis, although they meet the criteria of EAD. This approach does not take into account the complexity of the problem, missing the wider spectrum of graft dysfunction after liver transplantation. Therefore, attempts were made to modify these definitions, giving them a more dynamic character and also creating appropriate risk scores. These changes were aimed at better estimation of the risk of graft loss, especially in the critical period of 3 months after transplantation [20-27].

\section{Primary Nonfunction}

Researchers from King's College in London developed a nomogram that allows for the accurate diagnosis of PNF in patients after transplantation [24]. The study included a group of 1,286 patients who underwent liver transplantation. PNF was diagnosed in $3.7 \%$ of them. The created model was based on the albumin concentration at the time of transplantation, AST and lactate activity on posttransplant day 1, bilirubin concentration and INR value on day 3, and AST activity on day 7 . The created formula was compared with the criteria developed by the National Health Service (NHS) in Great Britain and the American criteria of the United Network for Organ Sharing (UNOS). The British model most effectively predicted the occurrence of PNF with a sensitivity of $73 \%$, which 
Table 1. Selected definitions of early posttransplant graft dysfunction

\begin{tabular}{|c|c|c|}
\hline Study & Year & Definition \\
\hline Deschenes et al. [14] & 1998 & $\begin{array}{l}\text { At least one of the following between } 2 \text { and } 7 \text { days after transplantation: } \\
\text { Bilirubin concentration }>10 \mathrm{mg} / \mathrm{dL} \\
\text { PT } \geq 17 \mathrm{~s} \\
\text { Symptoms of hepatic encephalopathy }\end{array}$ \\
\hline Cieślak et al. [15] & 2009 & $\begin{array}{l}\text { At least one of the following during the first } 7 \text { days after transplantation: } \\
\text { AST activity }>2,500 \mathrm{U} / \mathrm{L} \\
\text { ALT activity }>2,500 \mathrm{U} / \mathrm{L} \\
\text { PT }<50 \%\end{array}$ \\
\hline Ploeg et al. [6] & 1993 & $\begin{array}{l}\text { Following values between } 2 \text { and } 7 \text { days after transplantation: } \\
\text { AST activity }>2,000 \mathrm{U} / \mathrm{L} \\
\text { PT } \geq 16 \mathrm{~s} \\
\text { Ammonia concentration }>50 \mu \mathrm{mol} / \mathrm{L}\end{array}$ \\
\hline Pokorny et al. [17] & 2000 & $\begin{array}{l}\text { Following values during the first } 3 \text { days after transplantation: } \\
\text { AST activity }>2,500 \mathrm{U} / \mathrm{L} \\
\text { Fresh frozen plasma supplementation }>2 \text { days } \\
\text { Bile production }<20 \mathrm{~mL} / \text { day }\end{array}$ \\
\hline Olthoff et al. [3] & 2010 & $\begin{array}{l}\text { At least one of the following during the first } 7 \text { days after transplantation: } \\
\text { Bilirubin concentration } \geq 10 \mathrm{mg} / \mathrm{dL} \text { on day } 7 \\
\text { INR } \geq 1.6 \text { on day } 7 \\
\text { AST activity }>2,000 \mathrm{U} / \mathrm{L} \text { during the first } 7 \text { days } \\
\text { AST activity }>2,000 \mathrm{U} / \mathrm{L} \text { during the first } 7 \text { days }\end{array}$ \\
\hline
\end{tabular}

was higher compared to the both American (sensitivity $66 \%$ ) and the British model (sensitivity $31 \%$ ). The specificity beyond $90 \%$ was still provided by all three formulas. The modified version, based on parameters taken only from the first 3 days after transplantation, was also useful, which facilitates the diagnosis of PNF at an earlier stage. Lock et al. [25] presented encouraging results of a study evaluating the usefulness of the maximum liver function capacity test in the immediate posttransplant period. This test is based on an evaluation of the hepatic metabolism of 13C-methacetin which is driven by the hepatic cytochrome P-450. The metabolite levels of this substance are assessed in the patient's exhaled air. Values of $\leq 64 \mu \mathrm{g} /$ $\mathrm{kg} / \mathrm{h}$ immediately after surgery and $\leq 42 \mu \mathrm{g} / \mathrm{kg} / \mathrm{h}$ in the first day after transplantation had a sensitivity of 1.0 $(0.31-1.0)$, specificity of $1.0(0.94-1.0)$, and a positive predictive value of $1.0(0.31-1.0)$ in the diagnosis of PNF, surpassing the diagnosis based on the activity of AST at the same time points. French authors from the Paul Brousse Hospital assessed the usefulness of the indocyanine green plasma disappearance rate (PDR-ICG) in the diagnosis of early complications after transplantation, including PNF [28]. The cutoff value for the predefined endpoints was set at $12.85 \% / \mathrm{min}$ during the first 5 days after transplantation. However, the authors pointed out that this test does not specifically assess the function of the liver itself, and its results also depend on the hepatic blood flow and bile secretion. Importantly, vascular complications or septic shock also lead to decreased PDR-ICG values. Experiences in using this test were also presented by Olmedilla et al. [29]. The primary endpoint was death within 30 days of transplantation or re-transplantation within 7 days. The analysis was conducted on the basis of the factors statistically significant in the multivariate analysis, which were the value of INR $>2.2$ and PDR-ICG $<10 \%$. One and 2 points were awarded for these values, respectively. A 4-level risk score (0-3 points) was created. In the group of patients with 3 points, the risk of death or re-transplantation was $50 \%$, and the diagnostic accuracy of the method in this group was $90 \%$. In the cohort of patients with lower scores ( $0-2$ points), the risk of death and re-transplantation did not exceed $12 \%$. 


\section{Early Allograft Dysfunction}

As mentioned previously, the most widely used definition today is that proposed by Olthoff et al. [3]. Therefore, it is often a point of reference for other authors. Croome et al. [23] assessed this definition in patients undergoing transplantation from DBD and DCD donors. DCD donors accounted for $10 \%$ of all transplants. Graft failure was defined as death or the need for re-transplantation within 6 months of transplantation. In the conclusions, the authors emphasized the usefulness of the analyzed definition but only in relation to $\mathrm{DBD}$ donors. Due to the usually high levels of transaminases and the higher incidence of biliary complications after transplantation from DCD donors, the definition of Olthoff does not seem sufficiently accurate in this population. It seems that a better prediction can be pinpointed by using INR value on day 7 . The value of $\geq 1.6$ was associated with a $37.5 \%$ risk of graft failure, while with values $<1.6$, graft failure occurred only in $6.7 \%$ of patients. Another modification of the Pittsburg's definition was proposed by Nicolau-Raducu et al. [22]. The study assessed graft failure during the first 6 months after transplantation. The classic model was not significantly related to the occurrence of the assumed endpoint. The definition was modified by the inclusion of higher aminotransferase activities in the first 7 days after surgery, 3,000 U/L for ALT and 6,000 U/L for AST, respectively. With the modified definition, EAD was found in $15 \%$ of patients, and statistically significant association with mortality and graft failure during 6 months after transplantation was revealed.

The dynamic model for the evaluation of the liver function was developed by the authors from Spain [21]. They named their formula as a model for early allograft function scoring (MEAF). For its creation, the maximum values of AST activity, INR, and bilirubin concentration during the first 3 days after transplantation were included. The calculated risk score allows for the gradual assessment of the severity of EAD on a scale from 0 to 10 . The MEAF score was significantly associated with death and the risk of graft loss in the 3-month period after transplantation. In the highest category (MEAF score $>8$ ), 40\% of patients died within 90 days, and the risk of graft loss was $31 \%$. The superiority of the MEAF score over the Olthoff criteria was also confirmed in the analysis by Jochmans et al. [30].

Another tool to assess the risk of the 3-month graft failure was developed by a team from the University of California in Los Angeles (UCLA) [20]. The 5-step model called liver graft assessment following transplan- tation (L-GrAFT) comprised data of 2,008 patients undergoing liver transplantation. The risk score was calculated based on the bilirubin concentration, AST activity, INR value, platelet count, and dynamic changes of selected parameters over time (normalization of AST activity and bilirubin concentration and increase in the platelet count). Parameters from the first 10 days after surgery were analyzed. L-GrAFT was compared with the Olthoff (EAD) definition and the MEAF score. The statistically significant superiority of the new model in predicting graft failure in the first 3 months after transplantation was shown. The $c$-statistic for L-GrAFT was 0.85 compared to 0.68 for EAD and 0.70 for MEAF. The simplified score using data from the first 7 days after transplantation (L-GrAFT7) was developed as well. Also this model turned out to be a more effective predictor (c-statistic 0.83 ) than EAD and MEAF score. LGrAFT7 was then validated on a group of 3,423 patients transplanted in various centers in the USA and Europe [26]. Its superiority compared to the EAD and MEAF scores was demonstrated.

Avolio et al. developed another dynamic model called the early allograft failure simplified estimation score (EASE score) [27]. It calculates the 90-day risk of graft failure defined as death or the need for re-transplantation, regardless of the cause. The model is divided into 5 classes (1-5), and it is based on the MELD score at the time of transplantation, AST activity, bilirubin concentration, platelet count, intraoperative packed red blood cell transfusions, postoperative vascular thrombosis of the hepatic vessels, and volume of the center. The dynamics of changes in selected parameters during the first 10 days after transplantation were also included. Fourteen centers in Italy (1,609 patients) composed the derivation set. Moreover, the risk score was validated in two hospitals in the UK (538 patients). The EASE score was compared with other available criteria, including among others L-GrAFT, MEAF score, $\mathrm{EAD}$, and donor age and MELD score. The created risk score showed superiority over all the others ( $c$-statistic 0.87 for the derivation cohort and 0.78 for the validation cohort). The EASE score successfully predicted graft failure in $87 \%$ of patients, precisely identifying those who require urgent re-transplantation. In another study, the postoperative MELD of at least 16 points on the fifth postoperative day was found to be a sensitive threshold in predicting graft loss within 3 months after transplantation $(\mathrm{AUC}=0.84)$ [31]. 


\section{Risk Factors}

\section{Ischemia-Reperfusion Injury}

Impaired graft function, including its most advanced form (PNF), is a clinical manifestation of ischemia-reperfusion injury (IRI) [32, 33]. In their paper, Ali et al. [32] from the University of Cambridge analyzed the influence of IRI on the results of liver transplantation. IRI was assessed from the biopsies taken during transplantation. The presence of severe IRI was statistically significantly associated with the occurrence of PNF, early graft dysfunction, and the need for 90-day re-transplantation. PNF and graft dysfunction occurred in the group with severe IRI in $9.1 \%$ and $54.5 \%$ of patients, respectively. In the group without IRI, there was no PNF, while graft dysfunction affected $13 \%$ of recipients. Also in the study of Ito et al. [33], the relationship between IRI and the presence of EAD was confirmed. In the cohort with moderate/severe IRI, EAD occurred in $42.9 \%$ of patients compared to $24.8 \%$ of those without or with minor IRI.

\section{Donor and Recipient-Related Factors}

In a study by Uemura et al. including 2,341 transplantations, PNF occurred in $2.2 \%$ of recipients [7]. Significant risk factors turned out to be the age and female sex of the donor, cold ischemic time (CIT), number of days of the donor's stay in the intensive care unit, the duration of the transplant, and the procedure incompatible with the main blood groups. Al-Freah et al. [24] in turn, demonstrated the importance of the following biochemical parameters related to PNF occurrence: serum albumin at the time of transplantation and AST activity, bilirubin and lactate concentrations, and INR values in the first 7 days after transplantation. On their basis, the authors created the aforementioned risk score. Oh et al. [34] analyzed a group of 424 patients with 17 cases of PNF (4\%). Independent risk factors were transplantations between different races (Caucasians and African-Americans) and the need for portal vein reconstruction with an iliac vein graft due to the presence of portal thrombosis in the recipient [34]. Ploeg et al. [6] from the University of Wisconsin in the group of 323 patients undergoing liver transplantation diagnosed initial poor graft function in $16 \%$ of patients, while PNF in another $6 \%$. In the multivariate analysis, the occurrence of initial poor graft function and PNF was associated with the use of reduced grafts, renal failure in the recipient, re-transplantation, older age of donors, longer preservation time, and graft steatosis. Other authors have also confirmed the negative impact of older donors and preoperative renal failure of the recipients $[3,9]$.
MELD is a recognized risk factor in patients undergoing liver transplantation, worsening the long-term outcome $[19,35]$. In a study by Olthoff et al. [3] MELD was also found to be an independent risk factor for EAD (OR 1.44 95\% CI: 1.01-2.05). In turn, in the study by Hoyer et al. [36], both MELD and the donor risk index (DRI) did not appear to be independent risk factors for EAD. However, MELD was a statistically significant factor that worsened the 1-year graft survival. On the other hand, the parameters that increased the risk of EAD were the donor's body mass index (BMI), the last pretransplant donor gamma-glutamyl transferase activity, graft steatosis, and CIT [36]. Adverse relationship between donor BMI, CIT $\geq 10 \mathrm{~h}$, and warm ischemia time $\geq 40 \mathrm{~min}$ and the frequency of EAD was also confirmed by Bastos-Neves et al. [37] in his analysis of 602 patients undergoing liver transplantation. The role of MELD and DRI in the context of EAD development was analyzed in a group of 310 patients by Croome et al. [38]. Both MELD and DRI were independent risk factors for EAD. Importantly, a statistically significant adverse effect of high DRI $(\geq 1.7)$ was shown only when such grafts were implanted in recipients with MELD $<15$ (EAD $25 \%$ vs. $6.15 \%$ for DRI $\geq 1.7$ and DRI $<1.7$, respectively). For recipients with a higher MELD score, the DRI value was not found to have an influence on EAD occurrence.

As mentioned above, graft steatosis is a risk factor for both PNF and EAD. Moreover, even 70\% of PNF may be associated with graft macrosteatosis, often presented with only minor changes $\leq 30 \%$ [39]. Microsteatosis is also a recognized risk factor for impaired early graft function after transplantation [15]. Despite this, some authors stress the possibility of using such steatotic livers. Westerkamp et al. [40] compared a group of 19 patients who had grafts with moderate steatosis (30-60\% macrosteatosis) with a group of 95 patients who received grafts without any signs of steatosis. The study did not show any adverse effect of graft steatosis on the occurrence of PNF (5\% vs. $5 \%$ ). The use of such organs seems to be particularly safe in the case of a short CIT of less than $8 \mathrm{~h}$, which was reflected in lower activities of transaminases after transplantation. However, the authors did not assess the occurrence of PNF and EAD in groups with CIT longer and shorter than $8 \mathrm{~h}$. Moreover, McCormack et al. [41] proved that even grafts with extremely high steatosis (median $90 \%$ of macrosteatosis) can be successfully used. Although primary dysfunction of the graft (PDF; AST $>1,500 \mathrm{U} / \mathrm{L}$ with prothrombin time $\leq 50 \%$ within 7 days after transplantation) was more frequent in the steatotic group compared to the control group ( $30 \%$ vs. $10 \%), 60$ - 
day mortality as well as 1-year and 3-year patient and the graft survival was comparable between cohorts [41].

DCD donors along with older donors, donors with high BMI, or those with steatotic grafts are classified as so-called extended criteria donors (ECDs). The use of organs from DCD donors in multicentre analyses of large groups of patients is associated with worse long-term results [42]. In the work of Pitarch Martinez et al. [43], PDF occurred more often in recipients from the DCD group (60\% vs. $29.3 \%$ ), but the PNF frequency did not differ between groups. However, Bohorquez et al. [44] did not observe PNF in a group of over 100 transplants from DCD donors. On the other hand, a meta-analysis comparing DCD and DBD transplantations in recipients with chronic hepatitis $C$ showed a significant increase in the risk of PNF in the DCD group (OR 5.49, 95\% CI: 1.53-19.64) [45]. Duan et al. [46] analyzed the results of transplantation of patients with DCD grafts with moderate steatosis and without steatosis. Initial poor function occurred more frequently in the group with steatosis $(68.8 \%$ vs. 40.6\%), but the PNF risk and long-term results were comparable. In turn, in a study by Croome et al. [47], even mild (5-30\%) macrosteatosis in DCD donors increased the risk of EAD ( $56.8 \%$ vs. $45.6 \%$ ). The authors from Heidelberg drew attention to the different weighting of the criteria classifying the liver as ECDs. Steatosis $>40 \%$, CIT $>14 \mathrm{~h}$ and donor age $>65$ years were considered as major criteria. In the whole study group, there were no differences in the frequency of PNF between ECDs and nonECDs donors ( $2.7 \%$ vs. $4.0 \%$, respectively). However, in the group of patients with at least one major ECDs criterion, the frequency of PNF increased significantly $(2.4 \%$, $2.9 \%$, and $11.4 \%$ for 0,1 , and 2 major ECD criteria, respectively) [48].

\section{Other Factors}

The literature also indicates the role of the magnitude of apoptosis in the graft as a factor negatively associated with the occurrence of EAD [49]. Friedmann et al. [50] also noted an increased risk of EAD development in recipients with low levels of interleukin 6 and an inverse relationship with regard to interleukin $2 \mathrm{R}$ concentration. CIT is one of the well-established risk factors which negatively affect results of liver transplantation. However, duration of cold preservation is not the only driver. Also, the use of certain types of preservation solutions is associated with different risks. Both in the study by Van den Eynde et al. [51] and Adam et al. [52] based on the European Liver Transplant Registry data, the highest risk is associated with the use of histidine-tryptophan-ketoglu-

Graft Dysfunction after Liver

Transplantation tarate. Technical details of the procedure seem to play a role as well. Buchholz et al. [53] analyzed a group of 678 transplant patients and showed that the revascularization time is an important risk factor for EAD. The time of revascularization was defined as the time from the removal of the liver from the ice to reperfusion via the portal vein. A time of 44 min or longer was strongly associated with development of early graft dysfunction (OR 3.31, 95\% CI: 1.93-5.68), with a particularly negative effect when highrisk grafts were implanted [53]. Moreover, the first, very promising experiments with the use of molecular biology techniques as predictive factors are already present [54, 55].

\section{Mitigation Strategies}

As mentioned above, there are a number of risk factors associated with the development of early graft dysfunction. Many of them are not subject to modification, e.g., the age and type of the donor (DCD vs. DBD), the degree of graft steatosis, and MELD at the time of transplantation. Undoubtedly, the improvement of the results is a multifactorial process. This may be brought by the standardization of the transplant coordination and better allocation. The selection of the appropriate preservation solutions and the performance of the procedure by an experienced team are another crucial factors. Taken together, it translates into shorter ischemic times and lower risk of graft failure [38, 48, 51-53].

Since many key parameters cannot be modified, there is a continuing need for other methods to improve the treatment outcome. This is all the more important as ECD grafts are routinely used because of the organ shortage. As both PNF and EAD are primarily a consequence of the IRI, strategies to reduce ischemia-reperfusion injury are elements of utmost importance in the entire complex therapeutic process [56].

\section{Noninvasive Strategies}

One of the group of drugs assessed in the context of improving liver function are anesthetic drugs. In a multicenter, randomized clinical trial, patients undergoing liver transplantation from deceased donors were randomly assigned to anesthesia with propofol (48 patients) or sevoflurane [57]. Sevoflurane was started immediately after the end of induction and was used for the entire procedure, which fulfilled the definition of the conditioning (50 patients). EAD occurred more frequently in patients anesthetized with propofol, but this effect did not reach 
statistical significance ( $23 \%$ vs. $14 \%)$. A similarly favorable but also statistically insignificant influence of sevoflurane was found in decreasing the risk of severe complications (grades IIIb-V according to Clavien-Dindo classification: $50 \%$ vs. $40 \%$ ). Lang et al. [58] in a small randomized trial evaluated the effect of inhaled nitric oxide (iNO) in patients undergoing liver transplantation. The iNO group and the control group consisted of 10 people each. The use of iNO was associated with a statistically significant faster normalization of transaminases and coagulation parameters in the postoperative period. In a prospective study, Barthel et al. [59] assessed iloprost (prostaglandin I2 analog) in patients after liver transplantation. Around 80 patients (40 in the study and control group, respectively) were included. PDF was defined as bile production $<50 \mathrm{~mL}$ and AST activity $>1,500 \mathrm{U} / \mathrm{L}$ in the first $24 \mathrm{~h}$ after transplantation. Based on this definition, the frequency of graft dysfunction in the treatment group was nonsignificantly lower (5\% vs. $20 \%$ ). In the post hoc analysis, the definition of EAD (Olthoff) was used, also without significant differences in the diagnosis of EAD (27.5\% vs. $40 \%)$. Further, in a study conducted on a group of patients undergoing living donor liver transplantation (LDLT), no significant differences were found in the incidence of EAD in the group of recipients who received prostaglandin E1 (alprostadil) and in the control group. However, reduced risk of acute kidney injury was observed in the treatment group [60]. Korean researchers compared the use of alprostadil given intravenously and directly through the portal vein in patients undergoing LDLT [61]. Lower aminotranferases activity was observed in the first day after transplantation in the group that received the drug directly into the portal vein. Unfortunately, the presence of graft dysfunction was not specifically assessed. Santiago et al. [62] investigated the effect of $\mathrm{N}$-acetylcysteine (NAC) in patients undergoing liver transplantation. Fifty recipients were included, and half of them received NAC. The use of NAC and its hepatoprotective effect were associated with a significantly better profile of anti-inflammatory cytokines (interleukin 4 and 10), although the authors did not assess the occurrence of PNF and EAD, which limits the value of the study. The use of NAC was also studied in donors during organ procurement. In a randomized controlled trial, Gómez-Gavara et al. [63] found no differences in the incidence of EAD between the NAC group and the control group ( $31 \%$ vs. $37.4 \%)$. However, in the case of CIT greater than $6 \mathrm{~h}$, the use of NAC was associated with lower ALT activities after transplantation [63]. The use of NAC did not reduce the incidence of both EAD and PNF in a ran- domized trial involving 150 patients undergoing LDLT in India [64]. In another prospective randomized trial, the role of probiotics administered before liver transplantation was assessed. Despite better posttransplant aminotransferase and bilirubin values, rates of PNF were not statistically different between those treated with probiotics and the control group (placebo group) [65]. Not only probiotics but also antibiotics were assessed as a potential modifier of early liver function after transplantation. Ito et al. [66] assessed the use of rifaximin in 206 patients. The use of the antibiotic $\geq 28$ days significantly decreased the risk of EAD (10.3\% vs. $33.3 \%)$. The use of rifaximin $<28$ days was an independent risk factor for EAD development (OR 2.096, 95\% CI: 1.298-3.382) [66]. A small randomized clinical trial also revealed the potential benefits of L-carnitine administration in recipients listed for transplantation [67].

\section{Invasive Strategies}

Modulation of blood inflow to the liver by the induction of periods of controlled ischemia with subsequent reperfusion (ischemic preconditioning [IP]) is another strategy used to protect the liver. Amador et al. [68] assessed the potentially protective effect of the Pringle maneuver used in donors. The study comprised a group of 60 patients. The frequency of EAD has not been assessed. PNF was less common in the treatment group, although the difference was not statistically significant. In this group, better early liver function was also observed, revealed by a more favorable AST profile. Cescon et al. [69] also assessed IP in donors and came to similar conclusions. Although the IP group showed less pronounced IRI, the initial poor function and PNF were comparable between the two groups [69]. Robertson et al. [70] in their systematic review and meta-analysis evaluating donor IP demonstrated a beneficial effect of the intervention expressed by statistically significant lower AST activity in the early posttransplant period. Postoperative mortality, the risk of PNF, and the need for re-transplantation were also decreased, although the differences between the studied groups did not reach statistical significance [70].

Another intensively studied strategy to improve transplant outcomes is the use of machine perfusion. Both the hypothermic oxygenated perfusion (HOPE) technique and its variants and the normothermic machine perfusion (NMP) are currently being studied. Dutkowski et al. [71] compared HOPE perfusion of grafts from DCD donors (25 patients) with nonperfused livers from DCD donors (50 patients) and organs from DBD donors, which were also not perfused (50 patients). The median perfusion 
time was $118 \mathrm{~min}$. EAD assessed according to the Olthoff definition was significantly less common in the group subjected to perfusion ( $20 \%$ vs. $44 \%$ ), and its frequency was comparable to DBD donors. The risk of PNF did not differ between groups, although PNF occurred only in the nonperfused DCD group [71]. Patrono et al. [72] also confirmed the beneficial effect of HOPE on the early graft function after DBD transplantation. van Rijn et al. [73] achieved improved results using grafts from DCD donors perfused through both the portal vein and the hepatic artery (dual HOPE [DHOPE]). The DHOPE group and control group consisted of 10 and 20 patients, respectively. EAD did not occur in the perfused group, as compared to 2 patients in the control group (10\%). Graft post-reperfusion injury assessed by ALT activity or bilirubin concentration was significantly lower in the DHOPE group [73]. The meta-analysis by Zhang et al. [74] comparing hypothermic machine perfusion with the classic method of preservation (static cold storage) also confirmed the lower incidence of EAD in the group of perfused organs (OR $0.3695 \%$ CI: 0.17-0.75). Nasralla et al. [75] in a prospective randomized clinical trial compared the NMP with static cold storage. In the NMP group, EAD was significantly less common than in the control group with a frequency of $10.1 \%$ and $29.9 \%$, respectively (OR $0.263 ; 95 \%$ CI: 0.126-0.550) [75]. The use of normothermic regional perfusion (NRP) in donors prior to organ harvest was assessed by Savier et al. [76]. Briefly, NRP commences after donor is declared dead. During the first step, femoral vessels are cannulated. This is followed by abdominal organs perfusion while the surgical team is preparing for the organ recovery. The authors applied the technique to 50 DCD donors and compared it with the results of transplantations from DBD donors (100 patients). The early graft function, frequency of biliary complications, mortality, and graft loss within 90 days after transplantation did not differ between groups despite higher intrinsic risk of DCD donors. Muller et al. [77] compared HOPE perfusion with NRP. Before propensity score matching, EAD occurred more often in the HOPE group (68\% vs. $20 \%$ ), although the long-term patient and graft survival, the frequency of PNF, and biliary complications did not differ significantly between groups [77].

\section{Outcomes}

The occurrence of EAD worsens both early- and longterm outcomes, while PNF requires emergency re-transplantation as a life-saving procedure. Nanashima et al. analyzed a group of 93 patients and found significantly higher in-hospital mortality among patients with early graft dysfunction (35\% vs. 5\%) [16]. Moreover, in the case of PNF diagnosis, the mortality may reach even $90 \%$ [2]. In another study, the authors analyzed an impact of IRI on the outcomes of liver transplantation. Shorter 6-month both patient ( $97 \%$ vs. $88 \%$ ) and graft survival (99\% vs. $92 \%)$ in recipients who developed EAD was noted. Additionally, in the EAD group, the duration of intensive care unit and hospital stay were significantly longer, and the need for reoperation due to bleeding was more frequent as well as need for renal replacement therapy 3 months after transplantation [22]. The observations of other authors underline the negative relationship between graft failure and kidney function. Wadei et al. [78] using Acute Kidney Injury Network (AKIN) classification also confirmed the increased risk of acute kidney injury and chronic renal failure requiring renal replacement therapy in patients with EAD. In the analysis by Bastos-Neves et al. [37], early dysfunction significantly worsened also the 5 -year graft survival, with $60.5 \%$ in the EAD group compared to $74.3 \%$ in the non-EAD group. However, patient survival did not differ significantly between the groups [37]. EAD also has a major impact on long-term outcomes in transplantation from DCD donors [79].

\section{Conclusions}

Early dysfunction of the transplanted liver manifested by either PNF or EAD may be life-threatening conditions and yield long-term negative effects. The mechanism responsible for the occurrence of these complications is complex and is mainly based on IRI. Multiple variables playing a significant role have been studied so far. Some of them became pillars of recently created risk scores, which allow for faster diagnosis and implementation of appropriate treatment. Currently, there are no methods that would undoubtedly predict occurrence of graft dysfunction. In addition, most risk factors cannot be modified. Taken together, it is necessary to implement both noninvasive and invasive methods that can improve graft function and thus the transplant outcomes. This is all the more important as marginal organs are routinely used in the face of ongoing donor shortage. These organs are more susceptible to IRI and increase the risk of PNF/ EAD. Machine perfusion seems to have the greatest promise at the moment. However, the key is - as in any field of medicine - early diagnosis. 


\section{Conflict of Interest Statement}

Both authors declared that there are no conflicts of interest.

\section{Funding Sources}

The manuscript was created in the course of project funded by the National Science Centre, Poland (grant No. 2019/34/E/ NZ5/00433).

\section{References}

1 Haldar D, Kern B, Hodson J, Armstrong MJ, Adam R, Berlakovich G, et al. Outcomes of liver transplantation for non-alcoholic steatohepatitis: a European Liver Transplant Registry study. J Hepatol. 2019;71(2):313-22.

2 Hudcova J, Scopa C, Rashid J, Waqas A, Ruthazer R, Schumann R. Effect of early allograft dysfunction on outcomes following liver transplantation. Clin Transplant. 2017; $31(2)$.

3 Olthoff KM, Kulik L, Samstein B, Kaminski M, Abecassis M, Emond J, et al. Validation of a current definition of early allograft dysfunction in liver transplant recipients and analysis of risk factors. Liver Transpl. 2010;16(8):9439

4 Takaya S, Doyle H, Todo S, Irish W, Fung JJ, Starzl TE. Reduction of primary nonfunction with prostaglandin E1 after clinical liver transplantation. Transplant Proc. 1995;27: $1862-7$.

5 Strasberg SM, Howard TK, Molmenti EP, Hertl M. Selecting the donor liver: risk factors for poor function after orthotopic liver transplantation. Hepatology. 1994;20(4):829-38.

6 Ploeg RJ, D’Alessandro AM, Knechtle SJ, Stegall MD, Pirsch JD, Hoffmann RM, et al. Risk factors for primary dysfunction after liver transplantation: a multivariate analysis. Transplantation. 1993;55(4):807-13.

7 Uemura T, Randall HB, Sanchez EQ, Ikegami T, Narasimhan G, McKenna GJ, et al. Liver retransplantation for primary nonfunction: analysis of a 20 -year single-center experience. Liver Transpl. 2007;13(2):227-33.

8 Justo I, Nutu A, García-Conde M, Marcacuzco A, Manrique A, Calvo J, et al. Incidence and risk factors of primary non-function after liver transplantation using grafts from uncontrolled donors after circulatory death. Clin Transplant. 2021;35(1):e14134.

9 Johnson SR, Alexopoulos S, Curry M, Hanto DW. Primary nonfunction (PNF) in the MELD Era: An SRTR database analysis. Am J Transplant. 2007;7(4):1003-9.

10 Taner CB, Bathala V, Nguyen JH. Primary nonfunction in liver transplantation: a singlecenter experience. Transplant Proc. 2008; 40(10):3566-8.

\section{Author Contributions}

Łukasz Masior contributed to the manuscript's composition, literature review, and drafting and finalization of the manuscript. Michał Grąt contributed to the manuscript`s drafting and critical review.
11 Kemmer N, Secic M, Zacharias V, Kaiser T, Neff GW. Long-term analysis of primary nonfunction in liver transplant recipients. Transplant Proc. 2007;39(5):1477-80.

12 Available from: https://optn.transplant.hrsa. gov (accessed January 20, 2021).other

13 Chen XB, Xu MQ. Primary graft dysfunction after liver transplantation. Hepatobiliary Pancreat Dis Int. 2014;13(2):125-37.

14 Deschênes M, Belle SH, Krom RA, Zetterman RK, Lake JR. Early allograft dysfunction after liver transplantation: a definition and predictors of outcome. National institute of diabetes and digestive and kidney diseases liver transplantation database. Transplantation. 1998; 66(3):302-10

15 Cieślak B, Lewandowski Z, Urban M, Ziarkiewicz-Wróblewska B, Krawczyk M. Microvesicular liver graft steatosis as a risk factor of initial poor function in relation to suboptimal donor parameters. Transplant Proc. 2009; 41(8):2985-8.

16 Nanashima A, Pillay P, Verran DJ, Painter D, Nakasuji M, Crawford M, et al. Analysis of initial poor graft function after orthotopic liver transplantation: experience of an australian single liver transplantation center. Transplant Proc. 2002;34(4):1231-5.

17 Pokorny H, Gruenberger T, Soliman T, Rockenschaub S, Längle F, Steininger R. Organ survival after primary dysfunction of liver grafts in clinical orthotopic liver transplantation. Transpl Int. 2000;13 Suppl 1(Suppl 1):S154-7.

18 Busuttil RW, Farmer DG, Yersiz H, Hiatt JR, McDiarmid SV, Goldstein LI, et al. Analysis of long-term outcomes of 3,200 liver transplantations over two decades: a single-center experience. Ann Surg. 2005;241(6):905-16; discussion 916-8.

19 Agopian VG, Petrowsky H, Kaldas FM, Zarrinpar A, Farmer DG, Yersiz H, et al. The evolution of liver transplantation during 3 decades: analysis of 5,347 consecutive liver transplants at a single center. Ann Surg. 2013; 258(3):409-21.

20 Agopian VG, Harlander-Locke MP, Markovic D, Dumronggittigule W, Xia V, Kaldas FM, et al. Evaluation of early allograft function using the liver graft assessment following transplantation risk score model. JAMA Surg. 2018;153(5):436-44.
21 Pareja E, Cortes M, Hervás D, Mir J, Valdivieso A, Castell JV, et al. A score model for the continuous grading of early allograft dysfunction severity. Liver Transpl. 2015;21(1):3846.

22 Nicolau-Raducu R, Cohen AJ, Bokhari A, Bohorquez H, Bruce D, Carmody I, et al. Predictive model and risk factors associated with a revised definition of early allograft dysfunction in liver transplant recipients. Clin Transplant. 2017;31(11).

23 Croome KP, Wall W, Quan D, Vangala S, McAlister V, Marotta P, et al. Evaluation of the updated definition of early allograft dysfunction in donation after brain death and donation after cardiac death liver allografts. Hepatobiliary Pancreat Dis Int. 2012;11(4): 372-6.

24 Al-Freah MAB, McPhail MJW, Dionigi E, Foxton MR, Auzinger G, Rela M, et al. Improving the diagnostic criteria for primary liver graft nonfunction in adults utilizing standard and transportable laboratory parameters: an outcome-based analysis. Am J Transplant. 2017;17(5):1255-66.

25 Lock JF, Schwabauer E, Martus P, Videv N, Pratschke J, Malinowski M, et al. Early diagnosis of primary nonfunction and indication for reoperation after liver transplantation. Liver Transpl. 2010;16(2):172-80.

26 Agopian VG, Markovic D, Klintmalm GB, Saracino G, Chapman WC, Vachharajani N, et al. Multicenter validation of the liver graft assessment following transplantation (LGrAFT) score for assessment of early allograft dysfunction. J Hepatol. 2021;74(4):881-92.

27 Avolio AW, Franco A, Schlegel A, Lai Q, Meli $S$, Burra $P$, et al. Development and validation of a comprehensive model to estimate early allograft failure among patients requiring early liver retransplant. JAMA Surg. 2020; 155(12):e204095

28 Levesque E, Saliba F, Benhamida S, Ichaï P Azoulay D, Adam R, et al. Plasma disappearance rate of indocyanine green: a tool to evaluate early graft outcome after liver transplantation. Liver Transpl. 2009;15(10):1358-64. 
29 Olmedilla L, Lisbona CJ, Pérez-Peña JM, López-Baena JA, Garutti I, Salcedo M, et al. Early measurement of indocyanine green clearance accurately predicts short-term outcomes after liver transplantation. Transplantation. 2016;100(3):613-20.

30 Jochmans I, Fieuws S, Monbaliu D, Pirenne J. "Model for early allograft function" outperforms "early allograft dysfunction" as a predictor of transplant survival. Transplantation. 2017;101(8):e258-64.

31 Benko T, Gallinat A, Minor T, Saner FH, Sotiropoulos GC, Paul A, et al. The postoperative model for end stage liver disease score as a predictor of short-term outcome after transplantation of extended criteria donor livers. Eur J Gastroenterol Hepatol. 2017;29:716-22.

32 Ali JM, Davies SE, Brais RJ, Randle LV, Klinck JR, Allison ME, et al. Analysis of ischemia/reperfusion injury in time-zero biopsies predicts liver allograft outcomes. Liver Transpl. 2015;21:487-99.

33 Ito T, Naini BV, Markovic D, Aziz A, Younan $\mathrm{S}, \mathrm{Lu} \mathrm{M}$, et al. Ischemia reperfusion injury and its relationship with early allograft dysfunction in liver transplant patients. Am J Transplant. 2021;21(2):614-25.

34 Oh CK, Sawyer RG, Pelletier SJ, Pruett TL, Sanfey HA. Independent predictors for primary non-function after liver transplantation. Yonsei Med J. 2004;45:1155-61.

35 Grąt M, Wronka KM, Patkowski W, Stypułkowski J, Grąt K, Krasnodębski M, et al. Effects of donor age and cold ischemia on liver transplantation outcomes according to the severity of recipient status. Dig Dis Sci. 2016; 61:626-35.

36 Hoyer DP, Paul A, Gallinat A, Molmenti EP, Reinhardt R, Minor T, et al. Donor information based prediction of early allograft dysfunction and outcome in liver transplantation. Liver Int. 2015;35:156-63.

37 Bastos-Neves D, de Oliveira Salvalaggio PR, de Almeida MD. Risk factors, surgical complications and graft survival in liver transplant recipients with early allograft dysfunction. Hepatobiliary Pancreat Dis Int. 2019;18:4239.

38 Croome KP, Marotta P, Wall WJ, Dale C, Levstik MA, Chandok N, et al. Should a lower quality organ go to the least sick patient? model for end-stage liver disease score and donor risk index as predictors of early allograft dysfunction. Transplant Proc. 2012; 44:1303-6.

39 Kulik U, Lehner F, Klempnauer J, Borlak J. Primary non-function is frequently associated with fatty liver allografts and high mortality after re-transplantation. Liver Int. 2017;37: 1219-28.

40 Westerkamp AC, de Boer MT, van den Berg AP, Gouw AS, Porte RJ. Similar outcome after transplantation of moderate macrovesicular steatotic and nonsteatotic livers when the cold ischemia time is kept very short. Transpl Int. 2015;28:319-29.
41 McCormack L, Petrowsky H, Jochum W, Mullhaupt B, Weber M, Clavien PA. Use of severely steatotic grafts in liver transplantation. A Matched Case-Control Study. Ann Surg. 2007;246:940-6.

42 Taylor R, Allen E, Richards JA, Goh MA, Neuberger J, Collett D, et al. Survival advantage for patients accepting the offer of a circulatory death liver transplant. J Hepatol. 2019; 70:855-65.

43 Pitarch Martínez M, Sánchez Pérez B, León Díaz FJ, Fernández Aguilar JL, Pérez Daga JA, Montiel Casado MC, et al. Donation after cardiac death in liver transplantation: an additional source of organs with similar results to donation after brain death. Transplant Proc. 2019;51:4-8.

44 Bohorquez H, Seal JB, Cohen AJ, Kressel A, Bugeaud E, Bruce DS, et al. Safety and outcomes in 100 consecutive donation after circulatory death liver transplants using a protocol that includes thrombolytic therapy. Am J Transplant. 2017;17:2155-64.

45 Wells M, Croome KM, Janik T, HernandezAlejandro RM, Chandok NM. Comparing outcomes of donation after cardiac death versus donation after brain death in liver transplant recipients with hepatitis $\mathrm{C}$ : a systematic review and meta-analysis. Can J Gastroenterol Hepatol. 2014;28:103-8.

46 Duan X, Yan L, Shen Y, Zhang M, Bai X, Liang T. Outcomes of liver transplantation using moderately steatotic liver from donation after cardiac death (DCD). Ann Transl Med. 2020; $8: 1188$.

47 Croome KP, Mathur AK, Mao S, Aqel B, Piatt $J$, Senada $P$, et al. Perioperative and long-term outcomes of utilizing donation after circulatory death liver grafts with macrosteatosis: a multicenter analysis. Am J Transplant. 2020; 20:2449-56.

48 Lozanovski VJ, Khajeh E, Fonouni H, Pfeiffenberger J, von Haken R, Brenner T, et al. The impact of major extended donor criteria on graft failure and patient mortality after liver transplantation. Langenbecks Arch Surg. 2018;403:719-31.

49 Zhu Z, Tang Y, Huang S, Zhao Q, Schroder PM, Zhang Z, et al. Donor liver apoptosis is associated with early allograft dysfunction and decreased short-term graft survival after liver transplantation. Clin Transplant. 2018; 32:e13438.

50 Friedman BH, Wolf JH, Wang L, Putt ME, Shaked A, Christie JD, et al. Serum cytokine profiles associated with early allograft dysfunction in patients undergoing liver transplantation. Liver Transpl. 2012;18:166-76.

51 Van den Eynde J, Achtergaele J, Fieuws S, Jochmans I, Sainz-Barriga M, Monbaliu D, et al. The effect of organ preservation solutions on short-term outcomes after liver transplantation: a Single-Centre Retrospective Study. Transpl Int. 2021;34:327-38.
52 Adam R, Delvart V, Karam V, Ducerf C, Navarro $\mathrm{F}$, Letoublon $\mathrm{C}$, et al. Compared efficacy of preservation solutions in liver transplantation: a Long-Term Graft Outcome Study from the European liver transplant registry. Am J Transplant. 2015;15:395-406.

53 Buchholz BM, Gerlach UA, Chandrabalan VV, Hodson J, Gunson BK, Mergental H, et al. Revascularization time in liver transplantation: independent prediction of inferior short- and long-term outcomes by prolonged graft implantation. Transplantation. 2018; 102:2038-55.

54 Kurian SM, Fouraschen SMG, Langfelder P, Horvath S, Shaked A, Salomon DR, et al. Genomic profiles and predictors of early allograft dysfunction after human liver transplantation. Am J Transplant. 2015;15:160514.

55 Wang K, Wei X, Wei Q, Lu D, Li W, Pan B, et al. A two-circular RNA signature of donor circFOXN2 and circNECTIN3 predicts early allograft dysfunction after liver transplantation. Ann Transl Med. 2020;8:94.

56 Li J, Li RJ, Lv GY, Liu HQ. The mechanisms and strategies to protect from hepatic ischemia-reperfusion injury. Eur Rev Med Pharmacol Sci. 2015;19:2036-47.

57 Beck-Schimmer B, Bonvini JM, Schadde E, Dutkowski P, Oberkofler CE, Lesurtel M, et al. Conditioning with sevoflurane in liver transplantation: results of a multicenter randomized controlled trial. Transplantation. 2015;99:1606-12.

58 Lang JD Jr, Teng X, Chumley P, Crawford JH, Isbell TS, Chacko BK, et al. Inhaled NO accelerates restoration of liver function in adults following orthotopic liver transplantation. J Clin Invest. 2007;117:2583-91.

59 Bärthel E, Rauchfuss F, Hoyer H, Habrecht O, Jandt K, Götz M, et al. Impact of stable PGI analog iloprost on early graft viability after liver transplantation: a Pilot Study. Clin Transplant. 2012;26:E38-47.

60 Bharathan VK, Chandran B, Gopalakrishnan U, Varghese CT, Menon RN, Balakrishnan D, et al. Perioperative prostaglandin el infusion in living donor liver transplantation: a double-blind, placebo-controlled randomized trial. Liver Transpl. 2016;22:1067-74.

61 Shin M, Song SH, Kim JM, Kim SJ, Joh JW Lee S, et al. Effectiveness of intraportal prostaglandin E1 administration after liver transplantation. Transplant Proc. 2012;44:500-4.

62 Santiago FM, Bueno P, Olmedo C, MuffakGranero K, Comino A, Serradilla M, et al. Effect of $\mathrm{N}$-acetylcysteine administration on intraoperative plasma levels of interleukin-4 and interleukin-10 in liver transplant recipients. Transplant Proc. 2008;40:2978-80.

63 Gómez-Gavara C, Herraiz AM, Hervás D, Pérez-Rojas J, LaHoz A, López-Andújar R. The potential role of efficacy and safety evaluation of $\mathrm{N}$-acetylcysteine administration during liver procurement. The NAC-400 single center randomised controlled trial. Transplantation. 2021;105:2245-54. 
64 Thirunavayakalathil MA, Varghese CT, Bharathan VK, Chandran B, Nair K, Mallick $\mathrm{S}$, et al. Double-blind placebo-controlled randomized trial of $\mathrm{N}$-acetylcysteine infusion following live donor liver transplantation. Hepatol Int. 2020;14:1075-108265.

65 Grąt M, Wronka KM, Lewandowski Z, Grąt K, Krasnodębski M, Stypułkowski J, et al. Effects of continuous use of probiotics before liver transplantation: a randomized, doubleblind, placebo-controlled trial. Clin Nutr. 2017;36:1530-9.

66 Ito T, Nakamura K, Kageyama S, Korayem IM, Hirao H, Kadono K, et al. Impact of rifaximin therapy on ischemia/reperfusion injury in liver transplantation: a propensity score-matched analysis. Liver Transpl. 2019; 25:1778-89.

67 Khajeh B, Dashti-Khavidaki S, Nasiri-Toosi M, Mohammadi K, Jafari A. Effects of pretransplant L-carnitine supplementation on primary graft dysfunction in liver transplant recipients: a pilot, randomized, placebo-controlled clinical trial. Res Pharm Sci. 2019;14: 504-14.

68 Amador A, Grande L, Martí J, Deulofeu R, Miquel R, Solá $\mathrm{A}$, et al. Ischemic pre-conditioning in deceased donor liver transplantation: a prospective randomized clinical trial. Am J Transplant. 2007;7:2180-9.
69 Cescon M, Grazi GL, Grassi A, Ravaioli M, Vetrone G, Ercolani G, et al. Effect of ischemic preconditioning in whole liver transplantation from deceased donors. A pilot study. Liver Transpl. 2006;12:628-35.

70 Robertson FP, Magill LJ, Wright GP, Fuller B, Davidson BR. A systematic review and metaanalysis of donor ischaemic preconditioning in liver transplantation. Transpl Int. 2016;29: 1147-54.

71 Dutkowski P, Polak WG, Muiesan P, Schlegel A, Verhoeven CJ, Scalera I, et al. First comparison of hypothermic oxygenated perfusion versus static cold storage of human donation after cardiac death liver transplants: an international-matched case analysis. Ann Surg. 2015;262:764-70.

72 Patrono D, Surra A, Catalano G, Rizza G, Berchialla P, Martini S, et al. Hypothermic oxygenated machine perfusion of liver grafts from brain-dead donors. Scientific Reports. 2019;9:9337.

73 van Rijn R, Karimian N, Matton APM, Burlage LC, Westerkamp AC, van den Berg AP, et al. Dual hypothermic oxygenated machine perfusion in liver transplants donated after circulatory death. Br J Surg. 2017;104:907-17.

74 Zhang Y, Zhang Y, Zhang M, Ma Z, Wu S. Hypothermic machine perfusion reduces the incidences of early allograft dysfunction and biliary complications and improves 1-year graft survival after human liver transplantation. A meta-analysis. Medicine. 2019;98(23): e16033.
75 Nasralla D, Coussios CC, Mergental H, Akhtar MZ, Butler AJ, Karani J, et al. A randomized trial of normothermic preservation in liver transplantation. Nature. 2018;557:506.

76 Savier E, Lim C, Rayar M, Orlando F, Boudjema K, Mohkam K, et al. Favorable outcomes of liver transplantation from controlled circulatory death donors using normothermic regional perfusion compared to brain death donors. Transplantation. 2020;104:1943-51.

77 Muller X, Mohkam K, Mueller M, Schlegel A, Dondero F, Sepulveda A, et al. Hypothermic oxygenated perfusion versus normothermic regional perfusion in liver transplantation from controlled donation after circulatory death. First International Comparative Study. Ann Surg. 2020;272:751-8.

78 Wadei HM, Lee DD, Croome KP, Mai ML, Golan E, Brotman R, et al. Early allograft dysfunction after liver transplantation is associated with short- and long-term kidney function impairment. Am J Transplant. 2016;16: 850-9.

79 Lee DD, Singh A, Burns JM, Perry DK, Nguyen JH, Taner CB. Early allograft dysfunction in liver transplantation with donation after cardiac death donors results in inferior survival. Liver Transpl. 2014;20:1447-53. 